\title{
APRESENTAÇÃO
}

\section{Cursos de formação de professores de História: cenário internacional, configurações e avaliação}

History teacher's training courses: internacional scenary, settings and evaluation

\author{
Claudia Sapag Ricci* \\ Maria do Céu de Melo** \\ Paulo Eduardo Dias de Mello**
}

Este Dossiê tem como objetivo compartilhar com professores, educadores e demais interessados um conjunto articulado de textos com reflexões sobre as propostas de configuração e avaliação dos cursos para formação de professores de História problematizando o atual contexto e a trajetória histórica e experiências desenvolvidas no Brasil, em Angola, Portugal e na Alemanha.

Para tanto, reunimos um conjunto de pesquisadores da área de História e Educação desses países, com o intuito de traçar um panorama das questões que perpassam a formação de professores de História no âmbito internacional e no específico de cada um dos países contemplados.

A intenção é contribuir para o debate em torno dos cursos para formação de professores de História, propondo indagações e diálogos acerca das configurações que esses cursos vêm adquirindo nesses países, diante do processo de globalização e da expansão dos paradigmas da formação no contexto do Neoliberalismo, das novas formas de oferta, e das políticas de avaliação implementadas nestes contextos.

\footnotetext{
* Professora Associada da Universidade Federal de Minas Gerais (UFMG). Pesquisadora (LABEPEH - CP/FAE/UFMG). ricci.clau@gmail.com

** Diretora do Mestrado em Ensino de História para o $3^{\circ}$ ciclo do Ensino Básico e o Ensino Secundário, Universidade do Minho, Braga, Portugal. mariaceumelo@gmail.com

*** Doutor em Educação. Docente na Universidade Estadual de Ponta Grossa (UEPG). paulodemello04@gmail.com
} 
Uma das questões centrais do presente Dossiê é pensar, no contexto internacional, como são engendradas as políticas que informam as maneiras de regulação e controle dos cursos de formação de professores de História, em especial, a implementação de políticas de avaliação dos cursos. Nesse sentido os textos refletem os impactos, dilemas e desdobramentos da Declaração de Bolonha (1999) em diferentes contextos, e como afetam a formação de professores de História. Ao mesmo tempo, analisam-se as diferentes configurações que se forjam em cada lugar.

No artigo "Reflexões acerca do Ensino de História nos Programas Curriculares de Formação de Professores de História em Angola entre 2001 e 2012", a professora Rebeca Helena André (Universidade do Porto) apresenta e analisa a organização curricular do ensino de História dos magistérios Primários e dos Institutos Médios Normais de Educação (IMNEs) e os impactos na formação de professores em Angola ao longo dos anos de 2001 a 2012. O contexto da formação do professor de História em Portugal é tema em dois artigos. Em "A formação de professores de História em Portugal: práticas pedagógicas e investigativas", a professora Maria do Céu de Melo (Universidade do Minho) detalha a adoção de um sistema organizado em três ciclos de estudo ( $1^{\circ}$ Ciclo com a duração mínima de 3 anos - Licenciatura; $2^{\circ}$ Ciclo com a duração de 1 ano e meio a 2 anos - Mestrado; $3^{\circ}$ Ciclo - doutoramento com duração variável) e a articulação entre a formação histórica no $1^{\circ}$ Ciclo e o estágio do $2^{\circ}$ Ciclo que privilegia o desenvolvimento de competências pedagógicas e a dimensão investigativa na formação de um professor reflexivo, autônomo e pró-ativo na implementação de mudanças educacionais. O professor Hugo Miguel Ferreira Cardoso apresenta a perspectiva de quem vivenciou, como aluno, o percurso formativo do mestrado em Ensino de História pela Universidade do Minho no artigo "O Mestrado em Ensino da História na Universidade do Minho (Portugal): o testemunho de um (ex-)aluno".

O artigo "Formação do professor de História nos contextos alemão e brasileiro: algumas questões sobre a relação entre teoria e prática”, de autoria de Rosiane Ribeiro Bechler e Cristiani Bereta da Silva, também aborda a formação docente em História sob a ótica de quem a vivencia ou vivenciou, buscando um contraponto entre as experiências formativas, especialmente nas atividades de Estágio e Práticas de Ensino do Curso de História da Universidade do 
Estado de Santa Catarina (Udesc) e as duas etapas - estudos acadêmicos e prática - da formação docente de História na Alemanha.

No contexto brasileiro, destaca-se a necessidade de compreender e problematizar a relação entre a expansão e a avaliação dos cursos de História no Brasil, especialmente entre os anos de 2004 e 2014, em torno das discussões acerca dos critérios de avaliação para cursos de graduação, com ênfase nos cursos de formação de professores em História e o Bacharelado na mesma área. Essa é a temática central do artigo "A expansão e a avaliação dos cursos de História no Brasil”, de Paulo Eduardo Dias de Mello (UEPG) e Fabiane Robl (USP), que apresenta uma análise sobre a expansão dos cursos sob a ótica da categoria administrativa das Instituições de Educação Superior (público versus privado) e da organização acadêmica (Universidades, Centros Universitários, Faculdades e Institutos de Tecnologia). Na análise dos resultados das avaliações foram considerados o conceito Enade e o Conceito Preliminar de Curso (CPC) e se estabeleceu um contraponto entre os cursos de Formação de Professores de História e os Cursos de Bacharelado em História.

Claudia Maffini Griboski (UnB), no artigo "Os cursos de História na perspectiva da avaliação”, aborda as discussões acerca dos critérios de avaliação para cursos de graduação, com ênfase nos cursos de formação de professores em História e no Bacharelado na mesma área. A análise considera a implementação das Diretrizes Curriculares Nacionais para a formação de professores e o papel da avaliação na concretização das diretrizes identificando o marco legal do componente curricular, a definição de formação específica para os cursos de licenciatura e bacharelado, e os resultados da avaliação pelo Sistema Nacional de Avaliação da Educação Superior (Sinaes) como aspectos fundamentais e interligados na formação de professores. O artigo "Historiador e/ou professor de História: a formação nos cursos de graduação de História”, de Claudia Sapag Ricci (UFMG), focaliza a polêmica em relação à distinção entre bacharelado e licenciatura nos cursos de História e os projetos pedagógicos que, no final do século XX e início do século XXI, passam a incluir políticas de patrimônio histórico, preservação do meio ambiente e direitos à pluralidade e à cidadania cultural como fundamentais para a atuação do historiador, no contexto dos embates para a superação da dicotomia entre licenciatura e bacharelado.

Experiências no tocante à formação do professor de História desenvolvidas no âmbito do Programa Institucional de Bolsa de Iniciação à Docência 
(Pibid) são o foco da Seção Falando de História Hoje e apresentam a articulação de saberes e práticas de docentes da graduação e da Educação Básica. O artigo "Experiências docentes: Subprojeto História Capes/Pibid/USP", de autoria de Antonia Terra de Calazans Fernandes, Eva Aparecida dos Santos, Patrícia Cerqueira Santos e Renata Pellaes Corrêa, apresenta os impactos do modelo de formação sinalizado pelo Pibid na parceria entre o Departamento de História da FFLCH/USP e Escolas Públicas da cidade de São Paulo; o artigo "Relato de experiência do Pibid Interdisciplinar História, Geografia e Letras: olhares em convergência, vivências e aprendizados na educação básica”, de autoria de Carlos Augusto Lima Ferreira, Leonardo Silva Santa Rosa Macêdo, Lusanira Nogueira Aragão e Sandra Cristina Queiroz Pinheiro, analisa a experiência interdisciplinar vivenciada em duas escolas públicas do município de Feira de Santana, Bahia, desenvolvida pela Universidade Estadual de Feira de Santana (UEFS), e o artigo "Experiências curriculares e formação de professores: uma tessitura coletiva no âmbito do Pibid/UFES", de Arnaldo Pinto Junior, Katia Valeska Azevedo e Mônica Cardoso de Lima, apresenta relatos de experiências vivenciadas no âmbito do Pibid com a Licenciatura em História da Universidade Federal do Espírito Santo (UFES).

Por fim, a Entrevista com a professora Stela Maria Meneghel, Coordenadora-Geral de Controle de Qualidade da Educação Superior da Diretoria de Avaliação da Educação Superior do Inep, realizada por Fabiane Robl (USP), Paulo Eduardo Dias de Mello (UEPG), Claudia Ricci (UFMG) e Claisy Marinho-Araújo (UnB), tem como foco a discussão acerca da trajetória e perspectivas da Avaliação dos Cursos de História no Brasil, problematizando a formulação das políticas de avaliação, seus critérios e processos, e abrangendo semelhanças e diferenças entre os cursos de Bacharelado e de Formação de Professores de História.

Este Dossiê inscreve-se, portanto, no campo da discussão sobre a formação do professor de História, colocando em tela as políticas educacionais e os paradigmas educacionais que as informam, abordando a temática numa perspectiva internacional, buscando aprofundar, no caso brasileiro, as questões relativas à avaliação dos cursos de História.

Apresentação recebida em 21 de julho de 2015. Aprovada em 24 de julho de 2015. 